\title{
Driving factors of Asian international migration flows
}

\section{Abstract}

Migration from, to and within Asia are believed to capture many of the largest flows in the world yet very little is known about the specific patterns and factors contributing to them. In this paper, utilising recent estimates of five-year bilateral migration flows for all countries in the world, we focus on understanding how demographic, geographic and socio-economic factors are related to the size of bilateral flows in Asia. We conduct our analysis in three strands to differentiate migration: 1) amongst Asian countries, 2) from Asian countries to destinations outside the region, and 3) towards Asian countries from elsewhere in the world. After controlling for demographic, geographic and socio-economic variables, we find that large countries are important senders of migrants but not so for receiving migrants, distance has nearly the same effect for moves within Asia and for moves to countries outside the region, and Gross Domestic Product per capita in the destination is important for moves within Asia. 


\section{Introduction}

International migration is increasing and thriving in the Asian region yet the patterns and specific pathways remain largely unknown because flow data are unavailable for cross-national comparisons (Iredale, Guo, Rozario, 2003; Hugo, 2005; Charles-Edwards, Muhidin, Bell, \& Zhu, 2016). This problem has resulted in relatively little research on the patterns of international migration in the Asian region, which is surprising considering the region contains over three-fifths of the world's population and its increasing importance in the world's economy. While migration flow data are now starting to be gathered (e.g., Park, Dumont, \& Baruah, 2015) and research highlighting the differences of migration in Asia from elsewhere in the world (Liu-Farrer \& Yeoh, 2018), there remain severe limitations in the evidence and comparability of migration data due to inconsistencies in definitions and measurements.

The aim of this research is to provide a better understanding of the mechanisms driving migration within, from, and to the Asian region. We do so by analysing recently developed five-year bilateral migration flow estimates from 1990 to 2015 provided by Abel (2018; see also Abel, 2013; Abel \& Sander, 2014). These flow estimates were derived from information on birthplace-specific migrant population stocks, readily available for most countries in the Asian region. The analysis focuses on the factors contributing to the migration patterns and forms an invaluable basis for understanding the higher-level dynamics and complexity of migration in Asian countries. This is particularly relevant due to the heterogeneity of economic development and expansion of migration that has occurred in the region over the past two and a half decades (Amrith, 2017).

To address the aim of this paper, we identify the key mechanisms underlying Asian migration over the past 25 years. Following the format of IOM (2017, Chapter 3), we focus on three movements: international migration within Asia, international migration from countries in Asia to elsewhere in the world, and international migration from countries elsewhere in the world to Asia. In particular, we explore the relative importance of various demographic, geographic, and socioeconomic factors associated with the patterns of five-yearly bilateral migration flow estimates 
produced by Abel (2018). This is carried out by fitting three spatial interaction regression models applied to the three movements. We also explore how the parameters of the regression models vary over time.

\section{Background}

People undertake international migration for many reasons. Those who have a choice move for employment, family reunion or amenity reasons. Those lacking choice move to escape persecution or harm. In Asia, there are many types of voluntary migration, including for example, skilled migration, overseas contract workers, ethnic return migration, female marriage migration and tertiary education migration (Hugo, 2005; Lee \& Klein, 2017; Liu-Farrer \& Yeoh, 2018; Yeoh \& Lai, 2008). Forced migration and refugee movements also represent an important, albeit underresearched, part of the Asian migration system (Abbasi-Shavazi \& Kraly, 2018). According to Castles et al. (2014, p. 151), very few countries in Asia are considered attractive to immigrants born in other countries. Outside the Middle East, the exceptions are Brunei, Hong Kong, Japan, Singapore, South Korea and Taiwan. There are, however, many countries in Asia that send large numbers abroad, most notably China, India and the Philippines. Finally, while research on Asian migration is growing, there are very few comprehensive analyses of migration in this region (Castles et al., 2014, p. 171). Recent reports, such as the World Migration Report 2018 (IOM 2017, Chapter 3; see also CharlesEdwards et al., 2016) focus on birthplace-specific migrant population stocks obtained from national censuses as that is the information most readily available. However, with these data, the timings (periods) of the migration flows that comprise the migrant population stocks are unknown.

Reported statistics on international migration flows in Asia are largely non-existent, and for the few countries that provide them, the data collection systems and measurements are inconsistent with other countries. There are two main reasons for the inconsistencies. First, no consensus exists on what exactly is a 'migrant', so comparative analyses suffer from differing national definitions. This is particularly the case for a large proportion of migrants in Asia, where 
permanent migration pathways are restricted and temporary flows are the most dominant form of migration. Temporary migrants moving across Asia are often caught between having regular and irregular migration statuses due to a sudden loss of employment and financial difficulties in returning to their country of origin (Pietsch, 2015). Second, the event of migration is rarely measured directly. Often it is inferred from a comparison of places of residence at two points in time or from a change in residence recorded by a population or migration registration system. The challenge is compounded because countries use different methods of data collection (Bilsborrow et al., 1997). Migration statistics may come from a variety of administrative data sources (e.g., population registers, registers of foreigners, registers of nationals overseas, border statistics, pension or tax registers), population censuses or surveys. As Hugo (2005) emphasised over ten years ago in this journal, the general absence and poor quality of migration flow data is a major obstacle to understanding the patterns that are occurring across Asia.

To overcome the above data problems, researchers have been developing methods to estimate migration flows from other data, most notably, from migrant population stock data (Abel, 2013, 2017; Abel \& Sanders, 2014). These estimates provide an important starting point for understanding the complex international movements underlying the demographic change caused by populations residing outside their country of birth. They also provide the capability to identify the key mechanisms underlying the patterns of migration though fitting spatial interaction models (Wilson, 1971; Haynes \& Fotheringham, 1984; Bennett \& Haining, 1985; Sen \& Smith, 1995).

Spatial interaction models have been widely used model and to understand the factors contributing to internal (domestic) migration but, to date, have not been applied as readily to study international migration due to the data limitations described above. The exceptions can be split into two families. The first set of authors fitted a gravity models to a selection of predominantly western countries based on available, but unharmonised migration flow data (see for example the studies of Cohen, Roig, Reuman, \& GoGwilt, 2008; Kim \& Cohen, 2010; Mayda, 2010; Pedersen, Pytlikova, \& Smith, 2008). The second set of authors fitted gravity models to global data based on simple 
differences in bilateral migrant stocks. These differences act as proxies for origin-destination flows that 1) do not account for demographic changes in foreign born populations and 2) either ignore or take ad-hoc approaches to cope with declines in bilateral stocks that would otherwise result in a negative origin-destination migration flow (see Beine, Bertoli, \& Fernández-Huertas Moraga, 2016) for a detailed review of this literature and methods used to approximate flows from differencing bilateral stocks). To our knowledge there has been no modelling efforts thus far that has focused on international migration flows for the Asian region.

\section{Data}

\section{Migration Data}

According to the United Nations classification, Asia includes 50 countries located in the Central (5), Eastern (7), Southern (9), Southeastern (11), and Western (18) regions. Population sizes in Asia range widely from over one billion persons in both China and India to less than 500 thousand persons for Brunei and Maldives.

We used a recently developed set of estimates of country-to-country migration flows every five years from 1990-1995 to 2010-2015 (Abel, 2018). These indirect estimates were derived from data on bilateral country of birth migrant stocks taken from the United Nations between 1990 and 2015 (United Nations, 2016) and demographic accounting methods to control for births and deaths. The final estimates represent the minimum migrant transition flows required to match the changes in bilateral migrant stocks, accounting for natural demographic change. Moreover, the estimated bilateral migration flows into and out of each country sum to the net migration total in the World Population Prospects (WPP) produced by the United Nations (2017b). As the migration flow estimates represent transitions, they measure the count of migrants in origin country $i$ at the start of the time period and destination country $j$ at the end of the period. Intermediate moves via a third county $k$ during the interval or moves to a third country followed by a return move back to the migrants original origin country during the period are not captured. 
Plots of the total estimated migration flows within Asia, leaving Asia and arriving in Asia are shown in Figure 1. The migration flows within the region have risen considerably during the 25-year period, peaking in 2005-2010 at 14.05 million. This increase came after a dip in 1995-2000 during the Asian financial crises. The level of immigration to Asia is much lower and never rose above 2 million during the 1990-1995 to 2010-2015 periods. Levels of emigration from Asia were relatively similar to levels of migration within the continent in 1990-1995. However, by the end of the period there were considerably fewer migrants moving out of Asia than there were moving within Asia.

\section{[Insert Figure 1 Here]}

In Figure 2, a plot of the bilateral estimated migration flows for the 2010-2015 period is shown (plots for all periods are given in the Appendix). Countries are labelled using the International Organisation for Standardisation (ISO) three letter country codes. They are ordered by UN region, beginning with Central Asia, moving clockwise around to Eastern Asia and to the rest of the world. The flow direction is indicated by the chord arrow head. The size of chords at their base represents the value of the estimated bilateral migration flow. The lengths of the outside sector axis (measured in millions) are set to their maximum values over all five time periods to allow for an easier comparison of levels across time. There are a number of notable patterns including flows out of China and India to the rest of the world, from Southern Asia to oil-rich countries in Western Asia (Saudi Arabia, Qatar, Kuwait, Oman) and large flows out of Syria to neighbouring Turkey, Lebanon and Jordan.

\section{[Insert Figure 2 Here]}




\section{Measures Related to Migration}

To identify the key factors driving these patterns, we utilise variables related to each country's demographic composition, geographic setting, socio-cultural identity, and political-economic condition. The first group contains demographic measures in the origin and destination countries, including the population size, old age dependency ratio and an education index. The population and dependency ratio data were obtained from the United Nations (2017b). Measures on population size, commonly used in spatial interaction models, enable a control for the relative levels of expected migration, where typically areas that are more populous are associated with both higher immigration and emigration. In the case of Asia, however, industrialisation and economic development happened first to countries that are geographically small in size and relatively small in population, making them major migration receiving countries in this region (Hugo, 2005; Massey, 2003). The old age dependency ratio measure, calculated by dividing the population aged $65+$ years by the population aged 15-64 years, was selected to study possible impacts of different demographic age structures on size of migration flows, as younger populations may be expected to send relatively more migrants (Castro \& Rogers, 1984). For the final demographic variables we used the education index from the United Nations Human Development Report, which is calculated using mean years of schooling and expected years of schooling in each country. Education and skill levels are seen to be intertwined with migration in many aspects (Dustmann \& Glitz, 2011; Hugo, 2005). In particular, the demand for highly-skilled migrants, and corresponding policies used to attract these persons, is expected to increase over time in Asia (Castles et al., 2014, pp. 153-154), as is currently happening in Singapore and Taiwan (Yeoh \& Lai, 2008).

The second group contains the geographic measures of distance and contiguity that are related to each migration corridor. The levels of migration are expected to be higher between countries that share a border and that are relatively close to each other - as persons tend to have less information about relatively distant places and are less likely to move to a locale about which they have little or no prior information. Both of distance and contiguity measures were based on 
data from the Gravity database of the CEPII (Head \& Mayer, 2013). We used their weighted distance measure that accounts for the geographic distribution of population inside each nation when calculating the distance between two countries. The contiguity variable is a dichotomous variable with value one if two countries share a land border and zero if not.

The third group captures social and cultural linkages for each migration corridor. This group includes measures on migrant stocks, colonial history, shared languages and religions. Data on migrant population stocks were taken from the place of birth - place of residence estimates of the United Nations (2017a) and correspond with the migration flow corridor at the beginning of each period. In macro level migration studies, migrant stocks typically provide a proxy for the size of existing migrant networks and, hence, where larger bilateral migrant stocks are in place, larger migrant flows are expected. In the expansion of Asian migration, migrant connections and networks are known to have played an important role (Amrith, 2011). With many traditional emigration countries located in Asia, namely China, Philippines, India, Korea, Pakistan and Vietnam (Hugo, 2005, Table 2-5), we expect the migrant stock and network factors to be significant. Measures on colonial histories, shared languages and common religions were taken from the aforementioned the CEPII Gravity databases. We expect greater migration flows to occur between countries that have stronger historical, linguistic and religious linkages (see, for example, Skeldon 2000). The colonial and linguistic links were measured dichotomously, with the value one if countries shared a coloniser after 1945 (colonial link) or over nine per cent of both populations spoke a common language (linguistic link), and zero elsewhere. The religious links were measured as an index between zero and one, based on the common shares of religious groups in each set of countries for a given migration corridor. This measure was originally formulated by Disdier \& Mayer (2007).

The final group relates to the economic and political conditions in each country. We expect that countries with high GDP per capita have higher levels of inward migration. A neo-classical approach to migration studies suggests that moves usually occur towards more highly developed economies, or to economies where jobs are available (Massey, 1990; Massey et al., 1993). We used 
the measures of Gross Domestic Product (GDP) per capita in each origin and destination country, collected by the National Accounts Section of the United Nations Statistics Division. Our final measure was based on data from the Uppsala Conflict Data Program on the number of battle related deaths. In each country we used the number of deaths summed over five-year periods. We expect that as the number of battle-related deaths increases, the number of migration flows out of the country also increases, and the number of migration flows into the country declines.

\section{Models}

In order to better understand the patterns of migration, we regress the estimated bilateral flows on the set of demographic, geographic, socio-cultural, economic and political variables building on Zipf's (1946) original gravity model and other related spatial interaction models that have been developed for migration (Wilson, 1971; Haynes \& Fotheringham, 1984; Fotheringham \& O’Kelley, 1989; Bennett \& Haining, 1985). Our model is run on three strands of the data to differentiate between the role of factors on 1) migration flows between Asian countries ${ }^{1}$, 2) from Asian countries to destinations outside the region ${ }^{2}$ and 3 ) towards Asian countries from elsewhere in the world ${ }^{3}$. We use PseudoPoisson Maximum Likelihood (PPML) models to control for over dispersion and provide robust standard errors. Country origin and destination fixed effects are used as control variables in each model.

We denote the migration flow between origin $i$ and destination $j$ during time period $p$ in each of our three models as $y_{i j p}$. The full model that we fit to each of our three strands of the data can be written as

$$
\begin{aligned}
\log y_{i j p}= & \beta_{0}+\beta_{1}^{O} \text { ORIGIN }_{i}+\beta_{1}^{D} \text { DESTINATION }_{j}+\beta_{1}^{P} \text { PERIOD }_{p}+ \\
& \beta_{2}^{O} \log \text { POP }_{i t}+\beta_{2}^{D} \log \text { POP }_{j t}+\beta_{3} \log \text { DIST }_{i j}+\beta_{4} \text { CONT }_{i j}+ \\
& \beta_{5} \log \text { STOCK }_{i j t}+\beta_{6} \text { COLONY }_{i j}+\beta_{7} \text { LANG }_{i j}+\beta_{8} \text { RELIGION }_{i j}+ \\
& \beta_{9}^{O} \text { TDR }_{i p}+\beta_{9}^{D} \text { TDR }_{j p}+\beta_{10}^{O} \text { EDUCATION }_{i t}+\beta_{10}^{D} \text { EDUCATION }_{j t}+
\end{aligned}
$$




$$
\beta_{11}^{O} \log G D P_{i t}+\beta_{11}^{D} \log G D P_{j t}+\beta_{12}^{O} \log V I O L E N C E_{i t}+\beta_{12}^{D} \log V I O L E N C E_{j t}+\varepsilon_{i j p}
$$

where the $\beta_{1}$ terms correspond to the control variables for each origin, destination countries and time period (each treated as a separate category), and the remaining $\beta$ terms are used for the parameters of interest. We use $i j$ subscripts to correspond to variables that are specific to migration corridors and ip or $j p$ to correspond to variables in a given origin or destination country during period $p$. The $t$ notation is used to differentiate between period and stock measures, where $t$ corresponds to a measure at the beginning of period $p$. We include zero values of $y_{i j p}$ in order to model the size of the flows in all migration corridors of the selected strand of the data.

\section{Results}

The estimated parameters from the full models fitted to each strand of the data are shown in Figure 3 (not including the control variables). The points represent the parameter estimates and the error bands their uncertainty, as measures by plus or minus two standard errors. The estimate parameter values and standard errors are provided in Appendix B.

\section{[Insert Figure 3 Here]}

As the parameter estimates in Figure 3 are based on different variables with different scales of measurement, it is not possible to compare their relative importance in explaining the expected size of the migration flows in each corridor. In order to make such a comparison, we present in Figure 4 the standardised regression coefficient obtained by multiplying the estimated parameters in Figure 3 with twice the standard deviation of the observed predictor variable, a procedure suggested by Gelman \& Hill $(2007$, p. 57) for obtaining an approximate measure of the importance of each variable, controlling for all others in the model. Measures with higher (absolute) standardised coefficients can be considered to be of greater influence on migration flows. In the following text, 
we interpret the parameter estimates presented in Figure 3 and Figure 4 for each of the three models (i.e., within Asia, out of Asia, and into Asia).

\section{[Insert Figure 4 here]}

\section{Migration within Asia}

The parameter estimates corresponding to the origin population for the flows within Asia is positive, indicating that more populous countries are associated with higher levels of emigration to other countries in the region, controlling for the other factors in the model. The coefficient value of 2.61, where both the dependent and independent variables use a logarithmic transformation, implies that for a one per cent increase in the population in an origin country lead to a 2.61 per cent increase in emigration. The origin population size is a highly influential factor, as shown in Figure 4, exhibiting the largest absolute standardised parameter estimate of all the variables included in the model for the model fitted to flows within Asia.

The parameter estimate of the population size at the destination is close to zero $(-0.02)$. This result is largely unseen when modelling migration flows, where larger inward moves are usually associated with higher population sizes. However, in Asia, a number of countries with large populations - such as China, India and Indonesia - experience relatively low levels of immigration, whilst destination countries with smaller populations such as Singapore, Hong Kong, the United Arab Emirates and other small Gulf states have relatively high levels of immigration as a result of either rapid industrialisation of the 'tiger economies' or oil-driven economic development.

The distance parameter $(-1.00)$ is negative, indicating that further distances are associated with smaller migration flows. The positive contiguity parameter indicates that bordering countries are positively associated with higher migration flows within Asia. Both of these parameters follow our expectations. The negative distance parameter has the fifth largest absolute standardised parameter estimate (Figure 4). 
The migrant stock and colonial link variables both have positive coefficients $(0.31$ and 0.72 , respectively) implying higher migration flows between countries with the presence of migrant stocks or a common coloniser. The migrant stock variable is the third largest standardised parameter estimate. Linguistic and religious links between countries in Asia are relatively close to zero, when considering the relative sizes of their standard errors, indicating only a minor influence of these potential drivers on the expected levels of migration when controlling for all other factors in the model.

Origin countries with high old age dependency ratios are positively associated with higher levels of emigration to other countries in Asia (0.13). In destination countries the age structure effect is also positive (0.04), where higher old age dependency ratios are associated with higher levels of immigration (although parameter is relatively close to zero).

Countries with low levels of human capital, measured using an education index, are associated with higher levels of emigration, reflected by the negative coefficient in Figure $3(-6.37)$. The standardised coefficient for the origin education index is the fourth highest in the model, showing its importance in explaining migration flows within Asia. The sizable negative education origin effect aligns with the prevalence of low-skilled and poorly paid intraregional labour migration in Asia destinations. The estimated parameter for the education at the destination is positive (1.97), indicating expected higher prevalence of migration to destinations with higher levels of human capital.

The association between economic wealth, measured by GDP per capita, and outward flows was close to zero $(-0.03)$. The association between economic wealth and inward flows was much stronger. Here, the positive parameter estimate implies that a one per cent increase in the GDP resulted in an expected 1.15 per cent increase in inward migration from elsewhere in Asia. The absolute standardised coefficient for the destination GDP is the second highest in the model. Finally, countries with higher levels of violence are associated with higher levels of emigration, whilst the corresponding effect on levels of immigration is small with parameter estimates close to zero. 


\section{Migration from Asia}

The estimated population parameters are more pronounced in the model fitted to the migration flows from Asia to the rest of the world than to the migration flows within Asia. For emigration, the estimated parameter suggests a one per cent increase in the population size of an Asian country was associated with a 3.71 per cent increase in the outward flow to a country outside of Asia, which was over a percent higher than a flow to another Asian country (Figure 3). For immigration, the estimated parameter suggests a one percent increase in the population size of a country out of Asia was associated with a 2.4 per cent increase in the inward flow from an Asia country, over two percent higher than the emigration to other Asian countries. The absolute standardised parameter estimates for the origin population coefficient and the destination population coefficient were the largest two amongst all the variables in the model fitted the data for flows from Asia to the rest of the world (Figure 4).

The distance parameter for migration flows out of Asia has a similar size negative coefficient $(-0.88)$ as that of the flows within Asia, indicating a broad equivalence in the average distance of migration flows in these two systems. The contiguity parameters for the flows out of Asia are negatively associated with higher migration flows, suggesting that moves out of Asia tend to occur over longer distances, jumping over neighbouring countries that border Asian region.

The migrant stock coefficient for migration flows heading out of Asia (0.53) is greater than the equivalent parameter for migration flows within the region, highlighting the relative importance of networks for migration flows out of the region. This is reflected in the standardised parameter estimate in Figure 4, where the migrant stock variable has the third largest absolute value. The effect of colonial linkages is negative and close to zero for moves out of Asia. Countries with 9 per cent of their population (or greater) speaking a common language are associated with larger flows heading out of Asia. Migration corridors between countries with similar religions are positively related with higher migration flows out of Asia. 
The parameter estimate for the old age dependency ratio in the origin countries has a very similar direction and value as those for moves within Asia. However, for destination countries outside Asia, higher old age dependency ratios are associated with lower migration inflows from Asian countries.

Both education variables differ in direction from the within Asia moves. Origin countries with higher human capital are associated with a small positive (close to zero) effect on larger migration outflows, whilst destination countries outside of Asia with low levels of human capital are strongly associated with higher migration inflows from Asia. The standardised destination education parameter is the fourth most important factor in explaining out of Asia moves.

Large migration flows out of Asia are positively associated with high levels of GDP per capita in origin countries. The role of GDP per capita in destination countries for moves out of Asia is far more subdued than for moves within the region, with a small positive association of higher GDP per capita to higher inflows to countries out of Asia. As with the out-of-Asia migration flows, countries with high levels of violence are associated with higher levels of outward migration flows from Asia to another region, although at lower levels on average. Non-Asia countries with low levels of violence are also associated with higher levels of inward migration flows from Asia, though both violence parameters are not so important in the model after standardisation (Figure 4).

\section{Migration to Asia}

As with migration both within and from Asia to the rest of the world, the estimated coefficient for the origin population size for migration into Asia from the rest of the world is positive. There is also a negative association between higher migration flows into countries with larger populations for moves into Asia. For this strand of the data, comprised of much smaller flows on average than the other two strands, the population at the destination (in Asia) has the largest standardised parameter. The distance parameter for migration flows into Asia is negative but smaller, implying shorter distance moves on average than in the other two data strands. The contiguity parameters for 
the flows into Asia from the rest of the world are negatively associated with higher migration flows but are relatively close to zero.

The migrant stock coefficient for migration flows into Asia from the rest of the world is close to the same size as the corresponding coefficient in the model fitted to migration flows within Asia. The effect of colonial linkages has a small but positive impact for moves into Asia. Countries sharing common languages are associated with larger flows towards Asia. The coefficient for the estimated language parameter is larger than in the other models, most likely driven by migration from Russian speaking countries in Europe moving to Asian countries in the former Soviet Union. Migration corridors between countries with similar religions are also positively associated with higher migration flows into Asia.

The estimated parameter size for the coefficient of origin countries' old age dependency ratios $(-0.21)$ suggests older non-Asia countries with high old age dependency ratios are associated with lower migration outflows towards Asia than younger countries. This differs from the results in the other models, where there was a positive association between old age dependency ratio of the origin country and the level of migration. The standardised parameter estimate for the origin country's old age dependency ratio is the third largest for the migration from the rest of the world to Asia model. Destination countries in Asia with high old age dependency ratios are also negatively associated with higher migration inflows from the rest of the world. The standardised parameter estimate for the destination country's old age dependency ratio is the fifth largest in the migration from the rest of the world to Asia model.

The estimated parameter for the origin education parameter (6.57) suggests that increase in the human capital of non-Asian countries were associated with higher migration flows to Asia. The standardised parameter estimate for the origin education parameter is the fourth largest in the migration into Asia model.

There is a negative association between migration flows into destination countries in Asia and GDP per capita of origin countries outside the region, suggesting a decrease in expected flows to 
Asia from rising economic growth outside the region. As in other migration flows, based on the other strands of the data, there was also a positive association between migration flows from origin countries and higher levels of violence. For education, economic growth and violence, the estimated parameters for the Asian destination countries (for flows from non-Asian countries) were close to zero.

\section{Time-Interaction Models}

In order to study changes in the drivers over time, we first replaced the categorical year predictor variable in the previous models with a continuous predictor variable centred (taking the value 0 ) for the 2000-2005 period, -2 in 1990-1995, -1 in 1995-2000, +1 in 2005-2010 and +2 in 2010-2015, and then interacted this predictor with each of the other predictor variables. These interaction effects, shown in Figure 5, provide some insight about the relative changes of each predictor variable over the 25-year period (1990-2015).

For flows within Asia, the time interaction effects of distance, contiguity, common language, old age dependency ratio (destination), education (destination) and GDP per capita (origin) declined between 1990-1995 and 2010-2015. The opposite was observed for population (origin), migrant stock, common religion, education (origin), GDP per capita (destination) and violence (destination). The time interaction effects for population size (destination), common colonizer, old age dependency ration (origin) and violence (origin) were all relatively stable over the period.

For flows out of Asia, the time interaction effects of population size (destination), contiguity, common colonizer, education (destination) and GDP per capita (origin and destination) and violence (destination) declined between 1990-1995 and 2010-2015. Increases in the time interaction effects occurred for the distance, migrant stock, common language and education (origin). For other variables, the time interaction effects were relatively stable.

Lastly, for flows into Asia, the time interaction effects for population size (origin and destination), common language, old age dependency ratio (destination), education (origin) and 
violence (destination) declined over the 25 year period. The corresponding time interaction effects of distance, contiguity, migrant stock, common colonizer, common religion, education (destination), GDP per capita (origin and destination) and violence (origin) increased.

In summary, the time-interaction parameters that exhibited distinct changes over time among all three types of migration flows were distance, contiguity, migrant stock, common language, education and GDP per capita. For example, the effect of language similarities decreased for migration flows arriving to Asian counties (either from within or from outside Asia) and increased for flows out of Asia. Also, there was a substantial increase over time on the role of migrant networks (measured by the migrant stock variable) on migration flows, in particular flows leaving Asian countries to destinations either within or outside of Asia.

\section{[Insert Figure 5 here]}

\section{Conclusion}

In this paper, we have explored the factors contributing to migration flows amongst Asian countries, from Asian countries to destinations outside the region, and towards Asian countries from elsewhere in the world. We believe this is the first empirical effort of its kind to attempt to compare the size of migration flows for the Asian regions with potential macro level drivers and to assess their changes over time.

We found that population size is the biggest factor contributing to migration in the Asian region. Small countries are disproportionally large receivers of migrants, whereas large countries are major senders. However, this may change in the future as China, India, and other large countries in the region are nearing or have already reached replacement level fertility rates, and many are expected to experience population declines within the next 35 years. Future supplies of emigrants are likely to be affected by labour shortages and aging issues in these major sending countries. As Zhu (2018) argues, we need to test our current theories of migration in the Asian context, and 
conduct more research on understanding how mobility patterns are changing in the midst of changing and large-scale economic development.

Migration networks, approximated with birthplace-specific migrant population data, are another important and positive driver for migration in the Asia region. It was more important for moves out of Asia than within or to Asia but this relationship appears to be changing over time. We also found some interesting patterns particular to the Asian region. For instance, we found that distance had nearly the same effect for moves out of Asia as within Asia. This may have to do with the large geographic scale of Asian region, making intra-region migration as distant as some interregion flows. Language and religious links are only important for moves into or out of Asia. GDP per capita at destination is big factor for moves within Asia but not so for other moves.

With the majority of studies on Asian international migration focusing on individual countries and micro-level mechanisms, this paper provides a much needed overview of the processes occurring at the macro level. We statistically showed that population size, migrant network, population age structure and economic and educational factors are among the most important drivers contributing to the size of international migration flows from, to and within Asia. The findings provide a unified macro-level perspective on international migration for Asia and align with what's been explored in country-level and micro-level analysis, particularly the role of relative deprivation, migrant networks and education (Czaika, 2012; Khadria, 2008; Oda, 2007; Hugo, 2008, 2011; Soe, Punpuing, Chamratrirng, \& Guest, 2011).

There are a number of limitations to our study. First, our regression coefficients are estimated based on a set of migration flow estimates, due to the absence of comparable reported data. The estimates represent the minimum number of migrant transitions required to match the changes in the given stock data, controlling for births and deaths in each country over the period. The true flow is likely to be higher as migrants return during the period or may be enumerated in the wrong the place in the demographic or migrant population stock data. The second limitation is that no account was made to distinguish different policy contexts across Asia to account for countries 
that are more restrictive in entry in relation to others, or those that have highly regulated temporary worker schemes.

In conclusion, this research has highlighted the important factors associated with trends of international migration within Asia, from Asian countries and to Asian countries. By understanding these factors, we have made progress in understanding the differences that occur amongst countries in Asia and also in relation to migration from and towards other places in the world.

\section{Notes}

\footnotetext{
${ }^{1}$ Based on 10,810 observations of migration flows between 47 origin countries to 46 destination countries over five time periods

${ }^{2}$ Based on 30,785 observations of migration flows between 47 origin countries to 131 destination countries over five time periods

${ }^{3}$ Based on 30,785 observations of migration flows between 131 origin countries to 47 destination countries over five time periods
} 


\section{References}

Abbasi-Shavazi, M. J., \& Kraly, E. P. (2018). Asia's under-researched forced and refugee migration, Asian Population Studies, 14(3), 229-231. doi:10.1080/17441730.2018.1483472.

Abel, G. J. (2010). Estimation of international migration flow tables in Europe. Journal of the Royal Statistical Society, Series A, 173(4), 797-825. doi:10.1111/j.1467-985X.2009.00636.x

Abel, G. J. (2013). Estimating global migration flow tables using place of birth data. Demographic Research, 28(18), 505-546. doi:10.4054/DemRes.2013.28.18

Abel, G. J. (2018). Estimates of global bilateral migration flows by gender between 1960 and 2015. International Migration Review. doi:10.1111/imre.12327

Abel, G. J., \& Sander, N. (2014). Quantifying global international migration flows. Science, 343(6178), 1520-1522. doi:10.1111/j.1467-985X.2009.00636.x

Amrith, S. S. (2011). Migration and diaspora in modern Asia. New York: Cambridge University Press.

Amrith, S. S. (2017). Colonial and postcolonial migrations. In G. Liu-Farrer \& B. S. A. Yeoh (Eds.), Routledge Handbook of Asian Migrations (pp. 21-32). Oxon: Routledge.

Beine, M., Bertoli, S., \& Fernández-Huertas Moraga, J. (2016). A practitioners' guide to gravity models of international migration. The World Economy, 39(4), 496-512. doi:10.1111/twec.12265

Bennett, R. J., \& R. P. Haining (1985). Spatial structure and spatial interaction models: Modeling approaches to the statistical analysis of geographical data. Journal of the Royal Statistical Society, Series A (Statistics in Society), 148(1), 1-36. doi:10.2307/2981508

Bilsborrow, R. E., Hugo, G., Oberai, A. S., \& Zlotnik, H. (1997). International migration statistics: Guidelines for improving data collection systems. Geneva: International Labour Office.

Castles, S., De Haas, H., \& Miller, M. J. (2014) The age of migration: International population movements in the modern world (5th ed.). London: Palgrave Macmillan.

Castro, L. G., \& Rogers, A. (1984). What the age composition of migrants can tell us. Research Report 84-3, International Institute for Applied Systems Analysis, Laxenburg. 
Charles-Edwards, E., Muhidin, S., Bell, M., \& Zhu, Y. (2016). Migration in Asia. In M. J. White (Ed.), International handbook of migration and population distribution (pp. 269-284). Dordrecht: Springer.

Cohen, J. E., Roig, M., Reuman, D. C., \& GoGwilt, C. (2008). International migration beyond gravity: A statistical model for use in population projections. Proceedings of the National Academy of Sciences, 105(40), 15269-15274. doi:10.1073/pnas.0808185105

Czaika, M. (2012). Internal versus international migration and the role of multiple deprivation: Some evidence from India. Asian Population Studies, 8(2), 125-149. doi:10.1080/17441730.2012.675678

Disdier, A. C., \& Mayer, T. (2007). Je t’aime, moi non plus: Bilateral opinions and international trade. European Journal of Political Economy, 23(4), 1140-1159. doi:10.1016/j.ejpoleco.2006.09.021

Dustmannm C., \& Glitz, A. (2011) Migration and education. In E. A. Hanushek, S. Machin, \& L. Woessmann (Eds.), Handbook of the economics of education, Volume 4 (pp. 327-439). Amsterdam: North Holland.

Fotheringham, A. S., \& O’Kelley, M. E. (1989). Spatial interaction models: Formulations and applications. Dordrecht: Kluwer Academic Publishers.

Gelman, A., \& Hill, J. (2007). Data analysis using regression and multilevel/hierarchical models. Cambridge: Cambridge University Press.

Haynes, K. E., \& Fotheringham, A. S. (1984). Gravity and spatial interaction models. Beverly Hills: Sage.

Head, K., \& Mayer, T. (2013). Gravity equations: Workhorse, toolkit, and cookbook. CEPII Working Paper No 2013-27. Centre D’Etudes Prospectives et D'Informations Internationales, Paris. Hugo, G. (2005). The new international migration in Asia: Challenges for population research. Asian Population Studies, 1(1), 93-120. doi:10.1080/17441730500125953

Hugo, G. (2008). In and out of Australia: Rethinking Chinese and Indian skilled migration to Australia. Asian Population Studies, 4(3), 267-291. doi:10.1080/17441730802496508 
Hugo, G. (2011). Migration and development in Malaysia: an emigration perspective. Asian Population Studies, 7(3), 219-241.

IOM (2017) World migration report 2018. Geneva: International Organization for Migration.

Iredale, R., Guo, F., \& Rozario, S. (2003). Introduction. In R. Iredale, F. Guo, \& S. Rozario (Eds.), Return migration in the Asia Pacific (pp. 1-25). Cheltenham: Edward Elgar.

Kim, K., \& Cohen, J. E. (2010). Determinants of international migration flows to and from industrialized countries: a panel data approach beyond gravity. International Migration Review, 44(4), 899-932. doi:10.1111/j.1747-7379.2010.00830.x

Khadria, B. (2008). India: Skilled migration to developed countries, labour migration to the gulf. In S. Castles \& R. D. Wise (Eds.), Migration and development: Perspectives from the South (pp. 79112). Geneva: International Organization for Migration.

Lee, B. S., \& Klein, J. L. (2017). Changing trends in international marriages between Korean men and Southeast Asian women, 1993-2013. Asian Population Studies, 13(3), 226-249. doi:10.1080/17441730.2017.1328863

Liu-Farrer, G., \& Yeoh, B. S. A. (2017). Routledge handbook of Asian migrations. Oxon: Routledge.

Marshall, M. G. (2017). Major episodes of political violence (MEPV) and conflict regions, 1946-2016. Vienna: Center for Systemic Peace.

Massey, D. S. (1990). Social structure, household strategies, and the cumulative causation of migration. Population Index, 56(1), 3-26. doi:10.2307/3644186

Massey, D.S. (2003). Patterns and processes of international migration in the 21st Century. Paper prepared for the Conference on African Migration in Comparative Perspective, Johannesburg, South Africa, 4-7 June.

Massey, D.S., Arango, J., Hugo, G.J., Kouaouci, A., Pellegrino, A., \& Taylor, J.E. (1993). Theories of international migration: A review and appraisal. Population and Development Review, 19(3), 431-466. doi:10.2307/2938462

Mayda, A. M. (2010). International migration: A panel data analysis of the determinants of bilateral 
flows. Journal of Population Economics, 23(4), 1249-1274. doi:10.1007/s00148-009-0251-x

Oda, H. (2007). Dynamics of internal and international migration in rural Pakistan. Asian Population Studies, 3(2), 169-179. doi:10.1080/17441730701500020

Park, J.-H., Dumont, J.-C., \& Baruah, N., Eds. (2015). Building human capital through labor migration in Asia. Tokyo: Asian Development Bank Institute.

Pedersen, P. J., Pytlikova, M., \& Smith, N. (2008). Selection or network effects? Migration flows into 27 OECD countries, 1990-2000. European Economic Review, 52(7), 1160-1186.

Pietsch, J. (2015). Irregular migration and public attitudes towards immigration in Europe. In J. Pietsch \& M. Clark (Eds.), Migration and integration in Europe, Southeast Asia and Australia: A comparative perspective (pp. 45-56). Amsterdam: Amsterdam University Press.

Sen, A., \& Smith, T. (1995). Gravity models of spatial interaction behavior. Berlin: Springer-Verlag. Skeldon, R. (2000). Trends in international migration in the Asian and Pacific region. International Social Science Journal, 52(165), 369-382. doi:10.1111/1468-2451.00266

Soe, K.K., Punpuing, S., Chamratrirong, A. \& Guest, P. (2011). The impact of migration on mobility of other family members in Thailand. Asian Population Studies, 7(2), 107-121. doi:10.1080/01621459.2013.789435

United Nations. (2016). International Migration Report 2015. New York: Population Division, Department of Economic and Social Affairs, United Nations.

United Nations. (2017a). International Migration Report 2017. New York: Population Division, Department of Economic and Social Affairs, United Nations.

United Nations. (2017b). World Population Prospects: The 2017 Revision, DVD Edition. New York: Population Division, Department of Economic and Social Affairs, United Nations.

Wilson, A. G. (1971). A family of spatial interaction models, and associated developments. Environment and Planning, 3, 1-32.

Yeoh, B. S. A., \& Lai, A.E. (2008). 'Talent' migration in and out of Asia: Challenges for policies and places (Guest Editor's Introduction). Asian Population Studies, 4(3), 235-345. 
doi:10.1080/17441730802496474

Zhu, Y. (2018). Advancing research on internal migration in Asia: The mobility transition hypothesis revisited. Asian Population Studies, 14(1), 1-4. doi:10.1080/17441730.2017.1328862

Zipf, G. K. (1946). The P1P2/D hypothesis: On the intercity movement of persons. American Sociological Review, 11(6), 677-686. doi:10.2307/2087063 

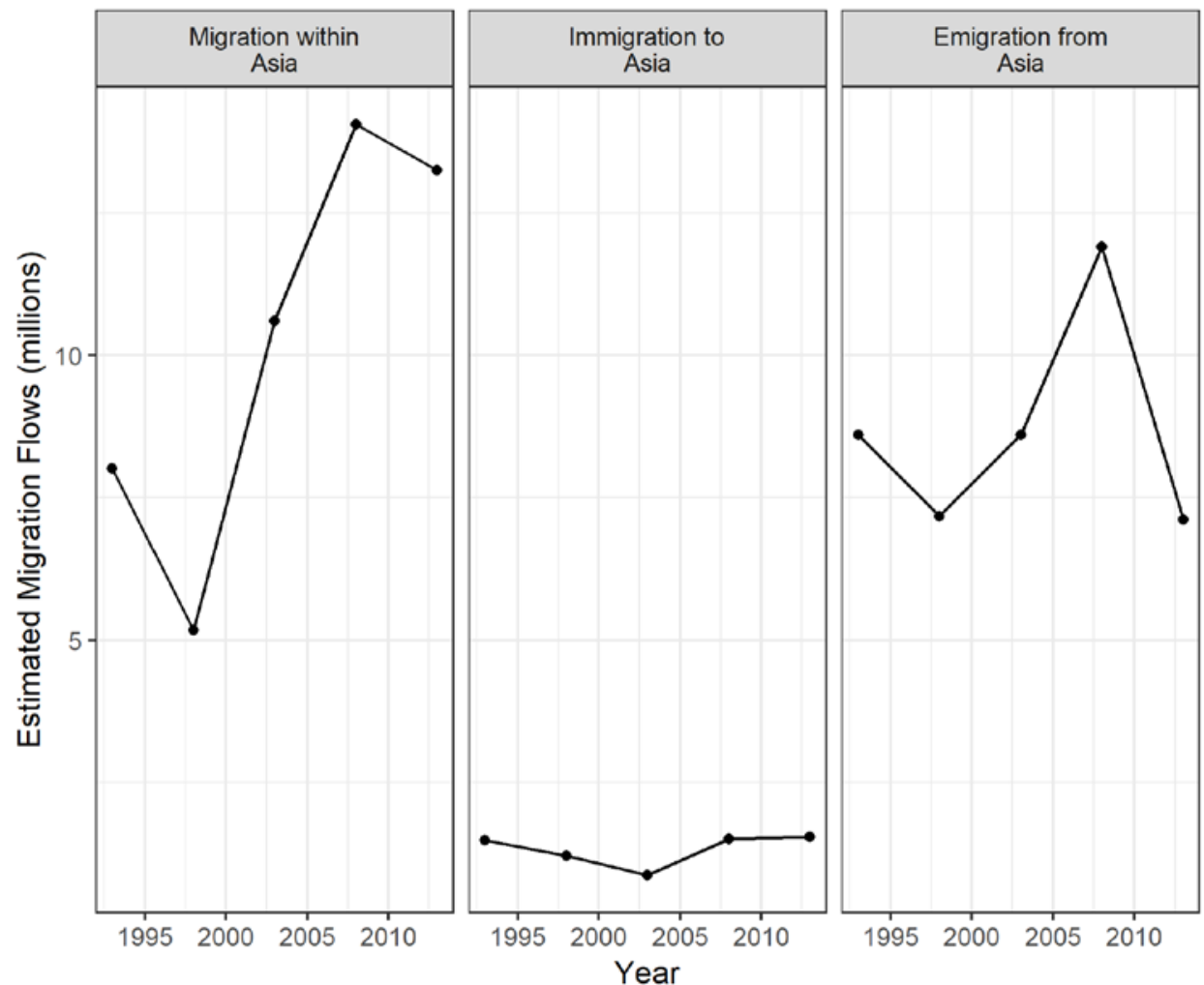

Figure 1: Estimated five-year international migrant transition flows (in millions) for Asia from Abel (2018). Note: points plotted at mid five-year interval on the horizontal axis 


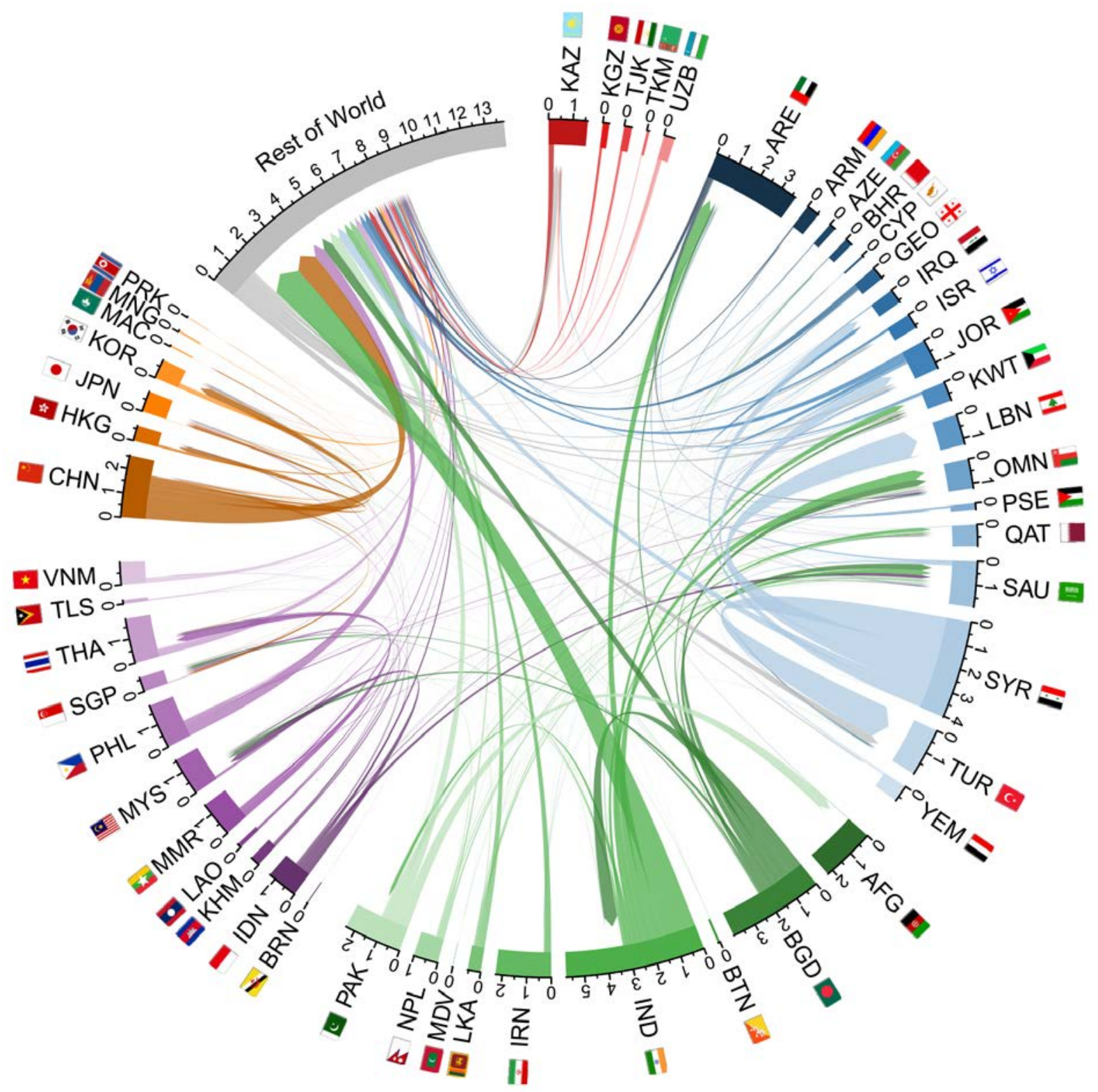

Figure 2: Estimated five-year Asian international migration flows (m) during 2010-2015 from Abel (2018) 


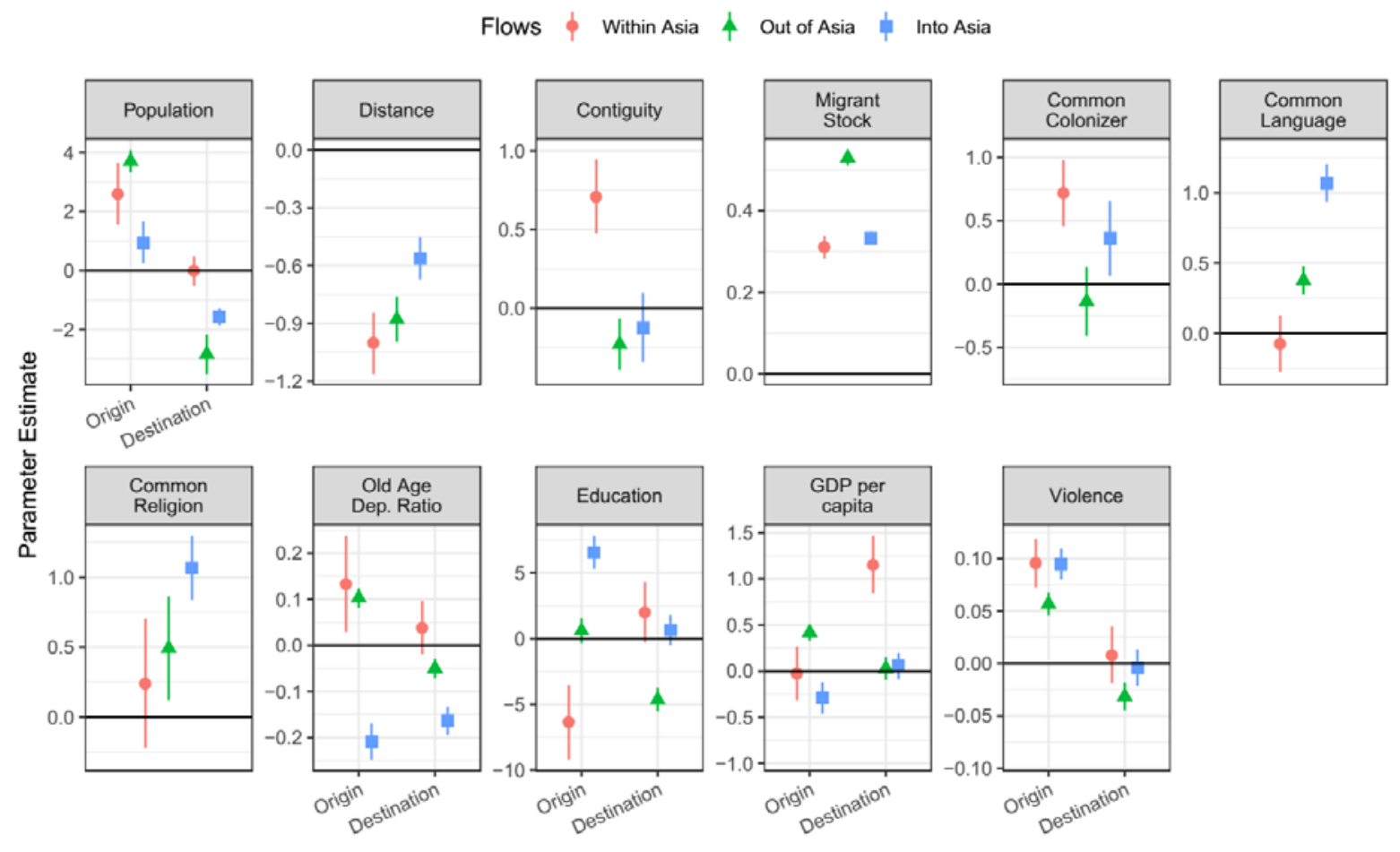

Figure 3: Parameter estimates and their standard errors from the full models.

Note: Error bars represent plus or minus two standard errors of the estimates 


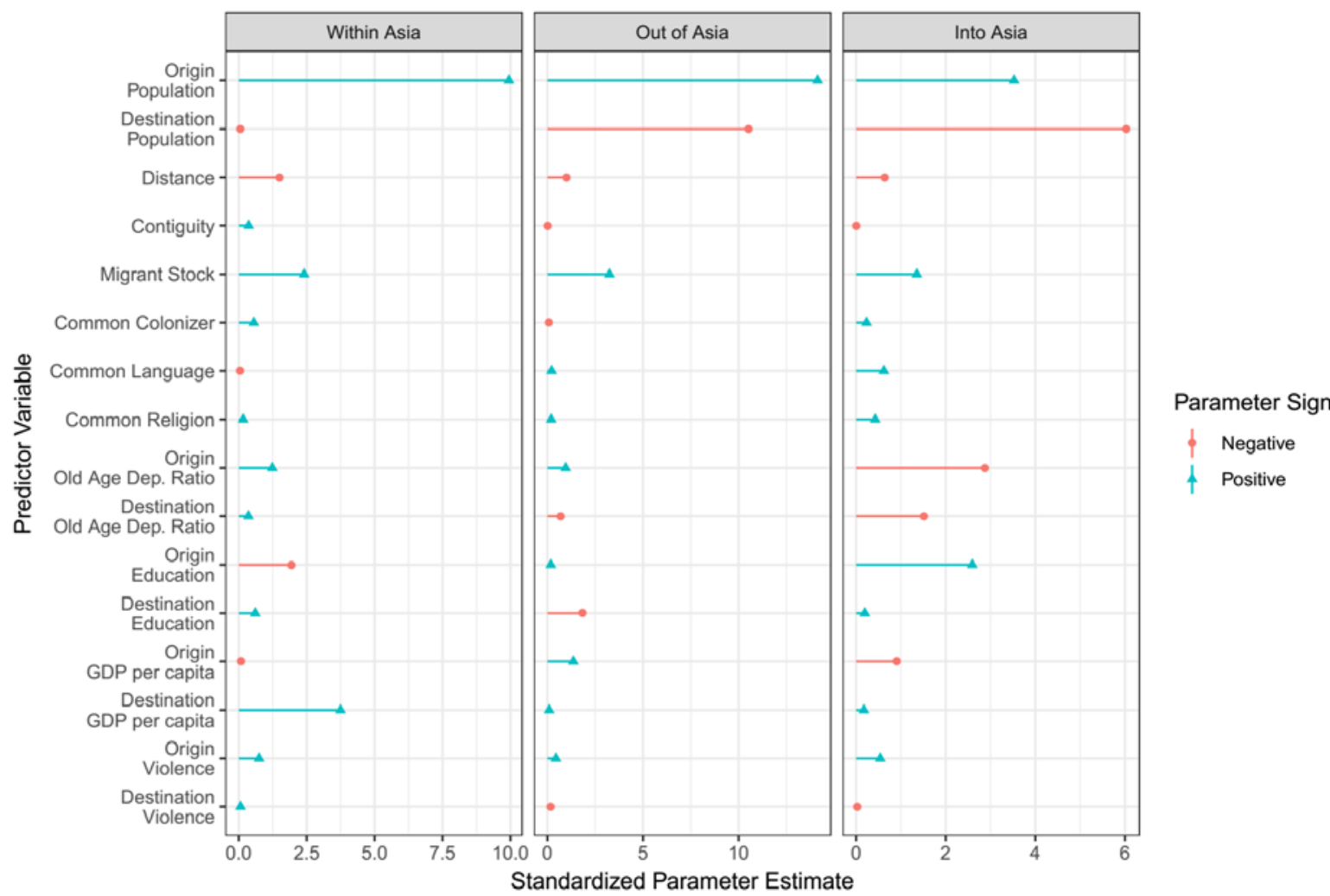

Figure 4: Standardised parameter estimates from the full models. 


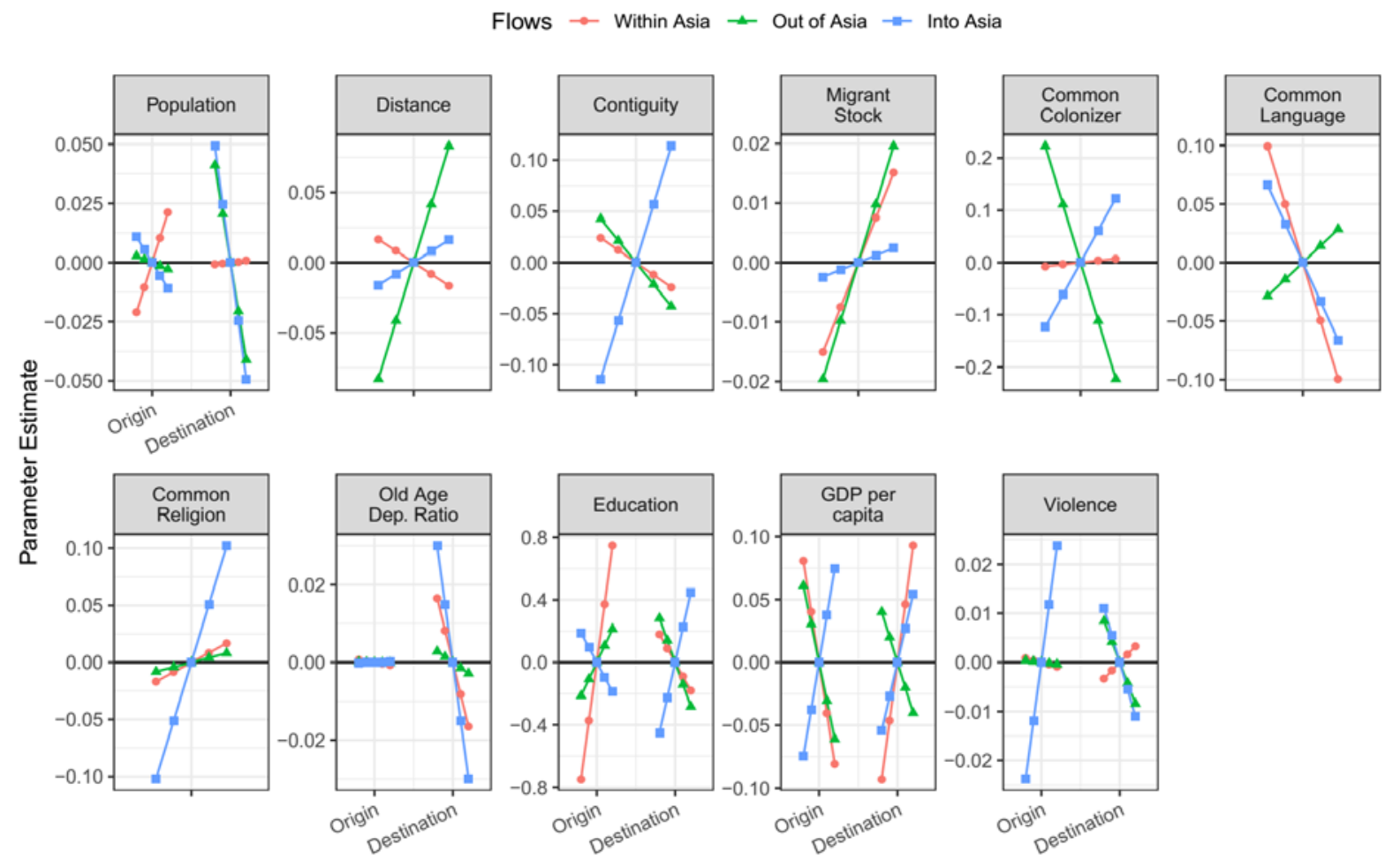

Figure 5: Estimated interaction parameter effects. The slopes show the changes in the estimated parameters for each variable during different time periods, adjusting for all other variables in the model. For each variable, the points on the far left represent the estimated parameter during 1990-1995 and point on the far right represent the estimated parameter during 2010-2015. All estimated parameters are zero during the reference period (2000-2005). 
Appendix A1: Estimated five-year Asian international migration flows ( $m$ ) during 1990-1995

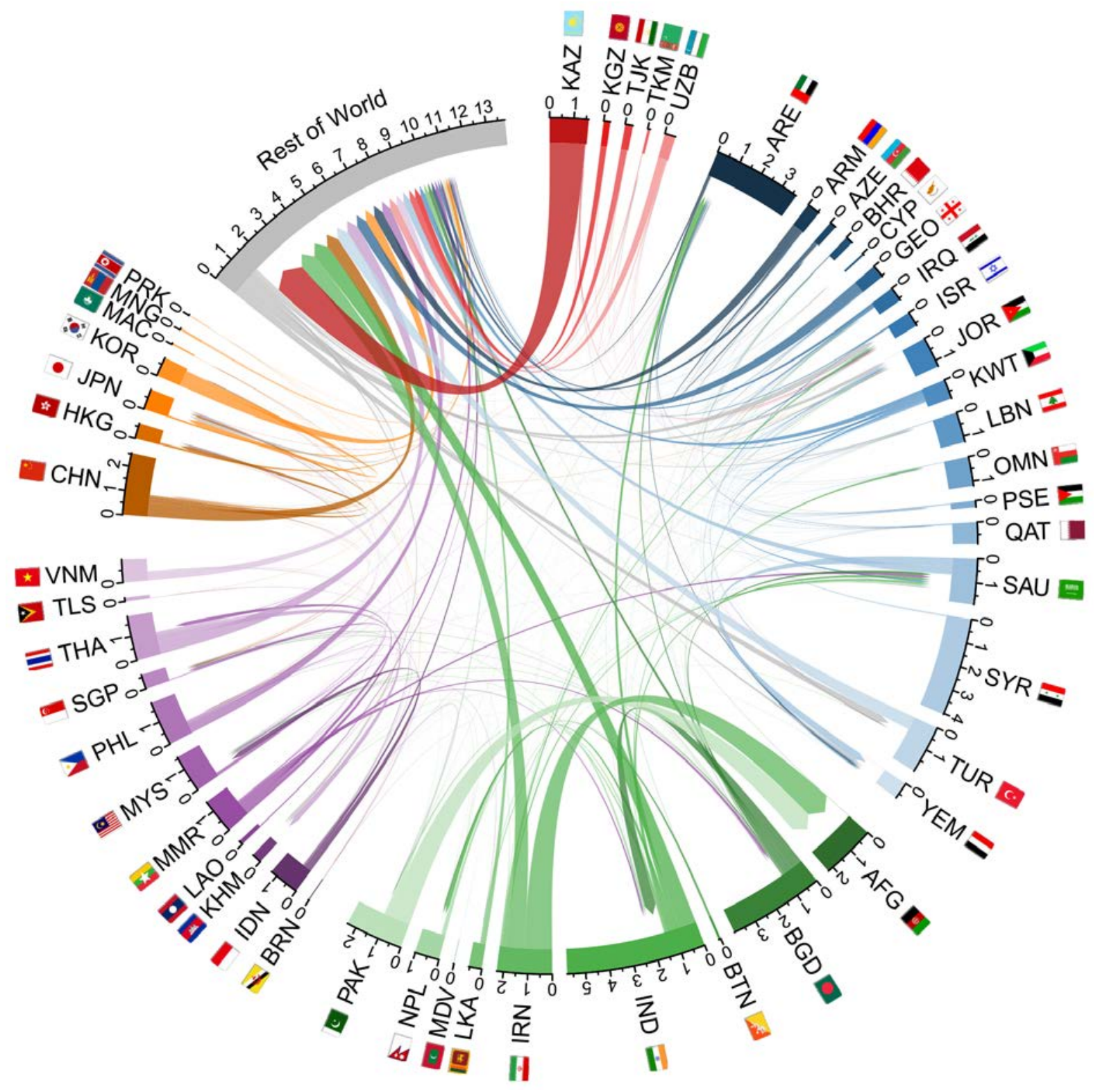


Appendix A2: Estimated five-year Asian international migration flows ( $\mathrm{m}$ ) during 1995-2000

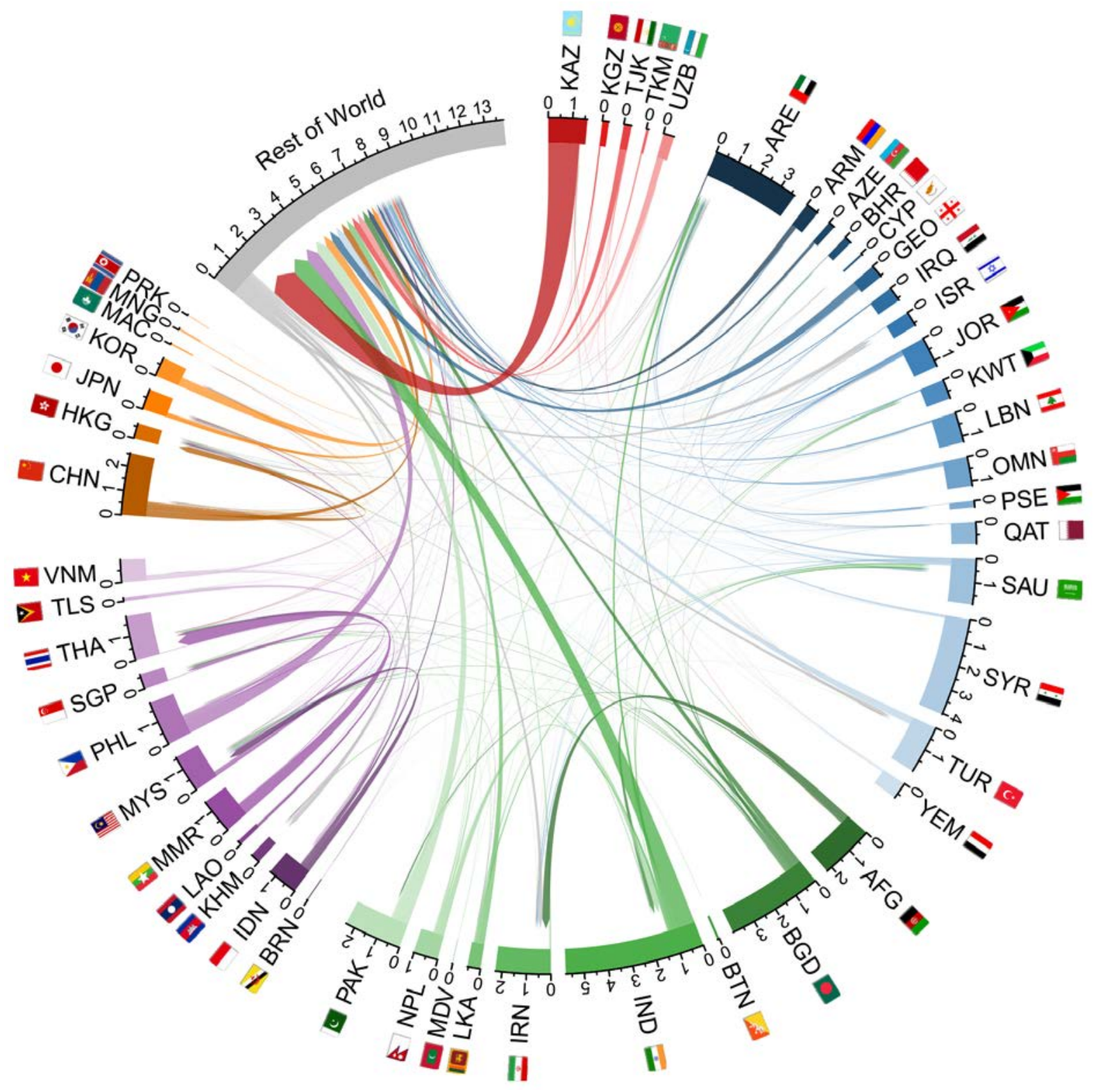


Appendix A3: Estimated five-year Asian international migration flows $(\mathrm{m})$ during 2000-2005

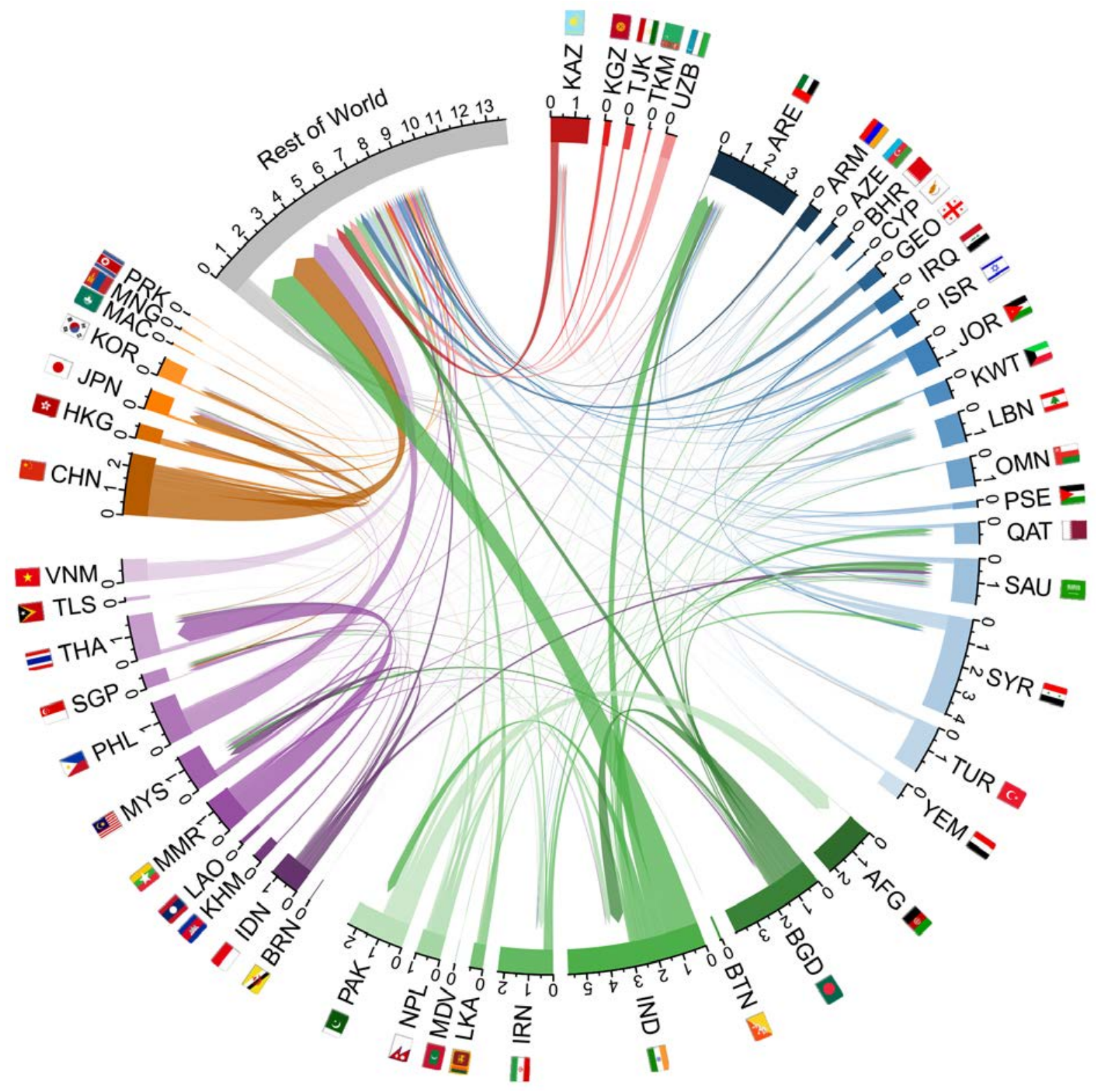


Appendix A4: Estimated five-year Asian international migration flows $(\mathrm{m})$ during 2005-2010

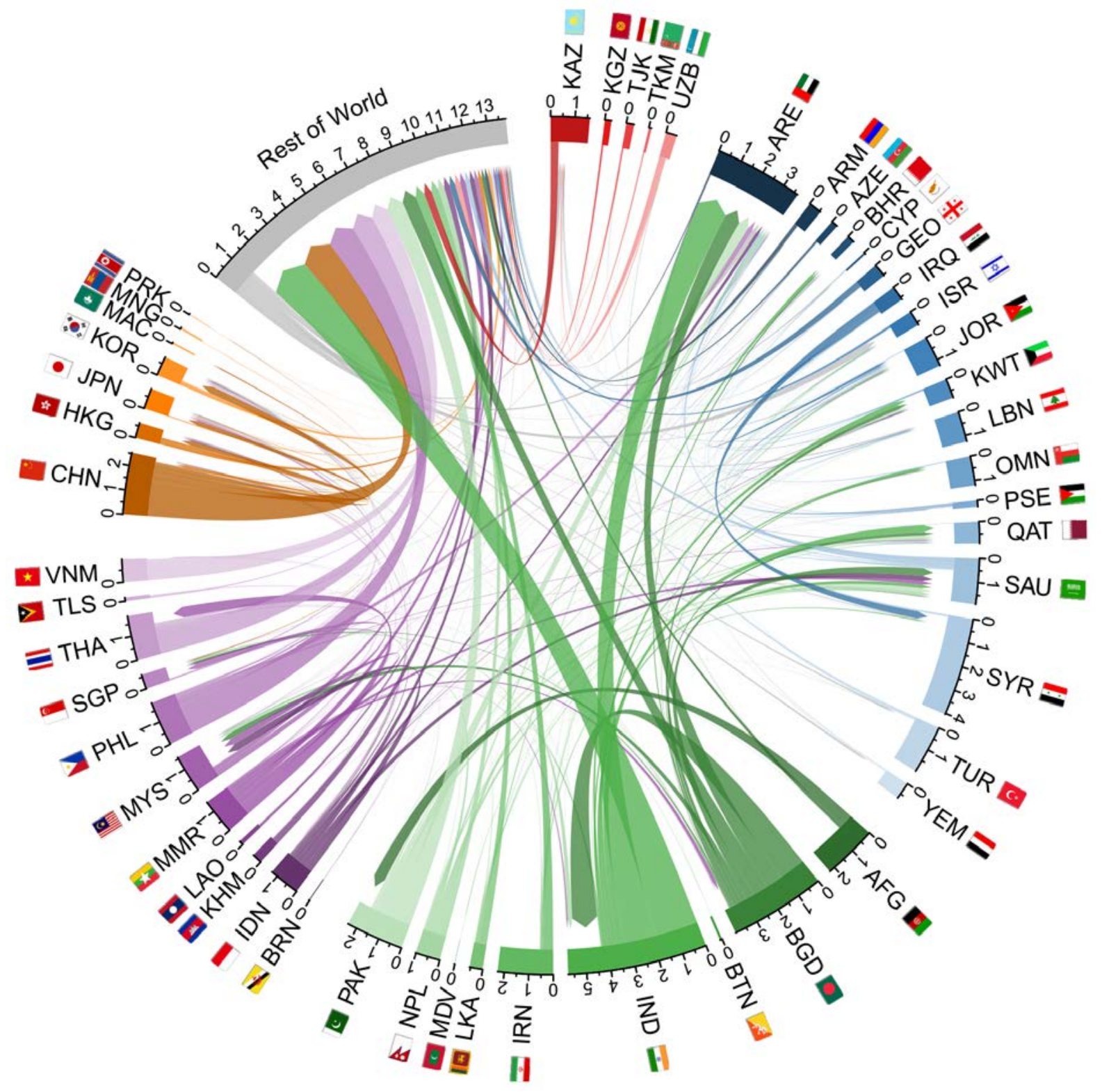


Appendix A5: Estimated five-year Asian international migration flows $(\mathrm{m})$ during 2010-2015

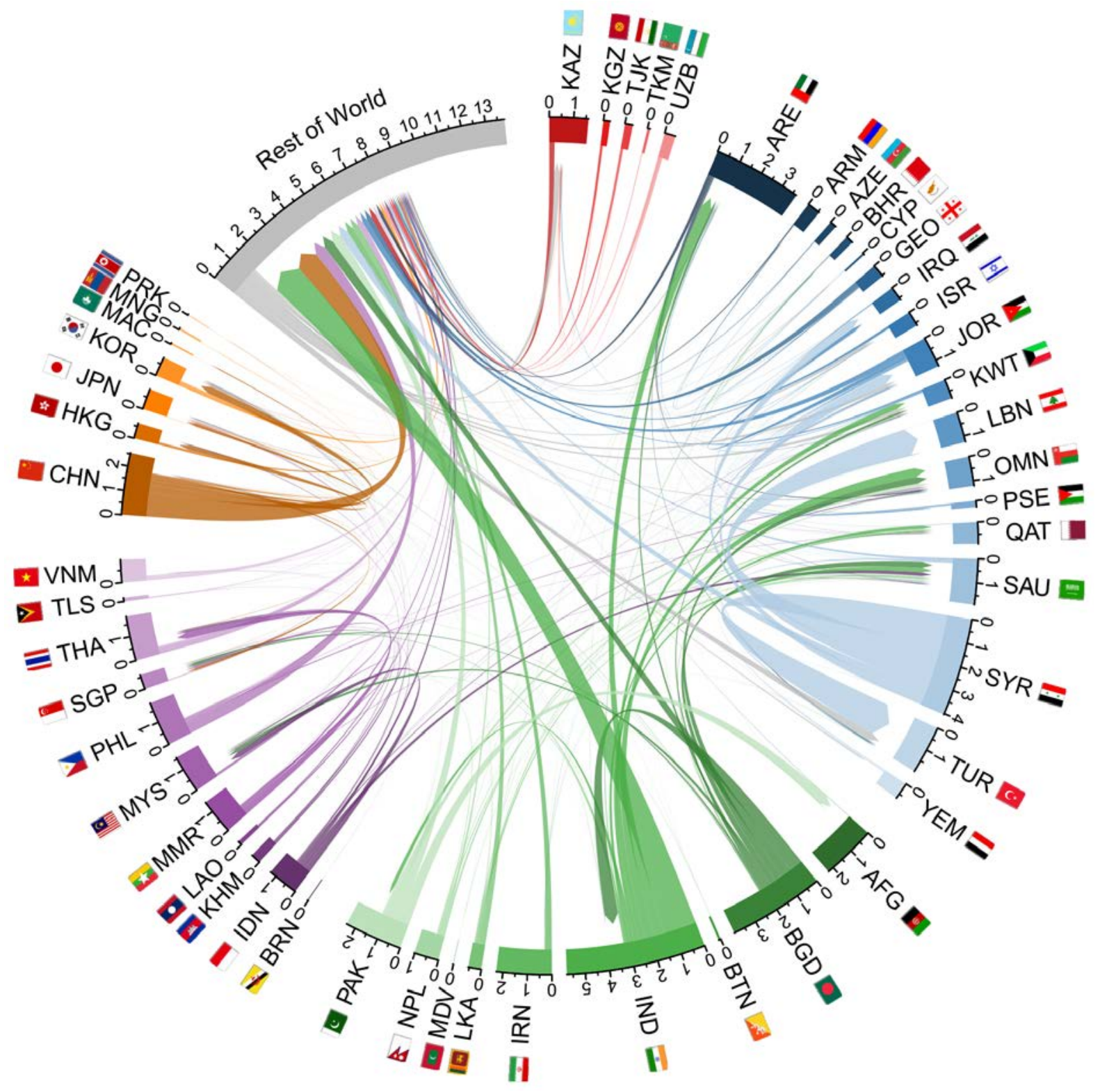


Appendix B: Parameters estimates, standard errors (in parenthesis) and statistics from model

\begin{tabular}{|c|c|c|c|}
\hline Parameter & Within Asia & Out of Asia & Into Asia \\
\hline \multirow[t]{2}{*}{ Population: Origin } & 2.612 & 3.711 & 0.951 \\
\hline & $(0.532)$ & (0.192) & $(0.364)$ \\
\hline \multirow[t]{2}{*}{ Population: Destination } & -0.015 & -2.838 & -1.583 \\
\hline & $(0.258)$ & $(0.340)$ & $(0.148)$ \\
\hline \multirow[t]{2}{*}{ Distance } & -1.002 & -0.878 & -0.561 \\
\hline & $(0.081)$ & $(0.061)$ & $(0.056)$ \\
\hline \multirow[t]{2}{*}{ Contiguity } & 0.711 & -0.229 & -0.122 \\
\hline & $(0.120)$ & $(0.084)$ & $(0.112)$ \\
\hline \multirow{2}{*}{ Migrant Stock } & 0.310 & 0.530 & 0.333 \\
\hline & (0.014) & (0.010) & $(0.008)$ \\
\hline \multirow[t]{2}{*}{ Common Colonizer } & 0.716 & -0.136 & 0.359 \\
\hline & $(0.134)$ & $(0.138)$ & $(0.151)$ \\
\hline \multirow{2}{*}{ Common Language } & -0.075 & 0.377 & 1.071 \\
\hline & $(0.102)$ & (0.051) & $(0.068)$ \\
\hline \multirow[t]{2}{*}{ Common Religion } & 0.240 & 0.492 & 1.067 \\
\hline & $(0.235)$ & (0.189) & $(0.117)$ \\
\hline \multirow{2}{*}{ Old Age Dep. Ratio: Origin } & 0.133 & 0.103 & -0.208 \\
\hline & (0.053) & (0.011) & $(0.020)$ \\
\hline \multirow[t]{2}{*}{ Old Age Dep. Ratio: Destination } & 0.038 & -0.050 & -0.164 \\
\hline & $(0.029)$ & (0.011) & $(0.015)$ \\
\hline \multirow[t]{2}{*}{ Education: Origin } & -6.366 & 0.581 & 6.564 \\
\hline & (1.454) & $(0.488)$ & $(0.636)$ \\
\hline \multirow[t]{2}{*}{ Education: Destination } & 1.996 & -4.658 & 0.639 \\
\hline & (1.170) & $(0.458)$ & $(0.580)$ \\
\hline \multirow[t]{2}{*}{ GDP per capita: Origin } & -0.026 & 0.418 & -0.292 \\
\hline & (0.148) & $(0.044)$ & $(0.088)$ \\
\hline \multirow[t]{2}{*}{ GDP per capita: Destination } & 1.154 & 0.029 & 0.054 \\
\hline & (0.159) & $(0.064)$ & $(0.072)$ \\
\hline \multirow[t]{2}{*}{ Violence: Origin } & 0.096 & 0.057 & 0.095 \\
\hline & $(0.012)$ & $(0.006)$ & $(0.007)$ \\
\hline \multirow[t]{2}{*}{ Violence: Destination } & 0.008 & -0.031 & -0.004 \\
\hline & (0.014) & $(0.007)$ & $(0.009)$ \\
\hline Origin Fixed Effects & 47 & 47 & 131 \\
\hline Destination Fixed Effects & 47 & 131 & 47 \\
\hline Period Fixed Effects & 5 & 5 & 5 \\
\hline Observations & 10810 & 30785 & 30785 \\
\hline Deviance & 74238143 & 30514027 & 13069162 \\
\hline
\end{tabular}

